\title{
STRATEGI PENGEMBANGAN EKOWISATA MANGROVE DI DESA RAWA MEKAR JAYA KECAMATAN SUNGAI APIT KABUPATEN SIAK PROVINSI RIAU
}

\author{
Mela Roza ${ }^{1}$, Dedi Hermon ${ }^{2}$, Triyatno ${ }^{3}$ \\ Program Studi Geografi, \\ Fakultas Ilmu Sosial, Universitas Negeri Padang \\ E-mail : Melaroza9@gmail.com
}

\begin{abstract}
ABSTRAK
Tujuan dari penelitian ini adalah (1) Menganalisis kesesuaian kawasan wisata untuk ekosistem mangrove untuk pengembangan ekowisata di Desa Rawa Mekar Jaya, Kecamatan Sungai Apit, Kabupaten Siak. (2) Menganalisis strategi dalam pengembangan ekowisata mangrove Rawa Mekar Jaya Kecamatan Sungai Apit Kabupaten Siak. Metode yang digunakan dalam penelitian ini adalah metode Kuantitatif. Metode pengumpulan data diperoleh dari hasil observasi, dan dokumentasi penelitian. Teknik pengambilan sampel yang digunakan adalah dengan menggunakan teknik stratified sampling. Hasil penelitian memperlihatkan bahwa Indeks Kesesuaian kawasan untuk Wisata mangrove di ekowisata mangrove Rawa Mekar Jaya tergolong ke dalam kategori Sesuai Bersyarat (SB). Pada stasiun 1 kesesuaiannya adalah $64 \%$, stasiun 2 kesesuaiannya ialah $61 \%$, stasiun 3 kesesuaiannya ialah 53\%, stasiun 4 kesesuaiannya ialah $58 \%$. Strategi pengembangan ekowisata mangrove di desa Rawa Mekar Jaya adalah meningkatkan upaya penanaman mangrove pada wilayah pengembangan ekowisata mangrove sehingga mangrove dapat memenuhi kriteria sangat sesuai untuk kawasan wisata yang baik berdasarkan Indeks Kesesuaian Wisata (IKW), meningkatkan partisipasi masyarakat lokal dalam mengembangkan kemampuan dan kreatifitas usaha wisata, seperti pembuatan souvenir dan mempromosikan wisata mangrove melalui internet dan media lainnya untuk menarik wisatawan, serta meningkatkan peran serta dinas terkait melalui penambahan sarana dan prasarana pendukung kegiatan wisata
\end{abstract}

Kata Kunci: Ekowisata, Mangrove, Analisis kesesuaian

\section{ABSTRACT}

The of aims research are (1) to analyze the suitability of tourism area for the mangrove's ecosystem in developing eco-tourism in Rawa Mekar region, district of Sungai Apit, Regency of Siak. (2) to analyze the strategy in developing mangrove eco-tourism in Rawa Mekar region, district of Sungai Apit, Regency of Siak. The method used in research is quantitative method. the method for collecting the data achieved by observation's result and research documentation. The technique in analyzing retrieval of sample using stratified sampling. The result shows that the index suitability for mangrove tourism in Rawa Mekar Jaya eco-tourism is categorizes as conditional suitable. Station 1 suitability is $64 \%$, station 2 suitability is $61 \%$, station 3 suitability is $53 \%$, station 4 suitability is 58\%. The strategy for developing mangrove eco-tourism is increase the mangrove plantings in mangrove eco-tourism development area so mangrove can fulfill the very appropriate area for a good tourism area based on the tourism index of suitability, increase the participation of local society in developing the ability and creativity of tourism business like creating souvenirs and promoting mangrove tourism which can be done through internet or other media in order to attract to tourist and increase the role of related officials through adding supporting facilities and infrastructures for the tourism activity.

Keyword: Ecotourism, Mangrove, Analysis the suitability

\footnotetext{
${ }^{1}$ Mahasiswa Program Studi Geografi

${ }^{2}$ Dosen Jurusan Geografi Fakultas Ilmu Sosial Universitas Negeri Padang, pembimbing I Dr. Dedi Hermon, M.P pembimbing II Triyatno, S.Pd, M.Si
} 


\section{PENDAHULUAN}

Indonesia merupakan salah satu negara yang memiliki hutan mangrove terbesar serta memiliki sumber daya hayati yang paling banyak. Mangrove juga memiliki dinamika karbon yang telah dipelajari dalam ekosistem mangrove selama beberapa dekade, studi penting yang menunjukkan bahwa tingkat penyimpanan karbon dihutan bakau indo-Pasifik melebihi dari kebanyakan ekosistem terestial. (Donato et al., 2011).

Sejak dipublikasikan artikel mengenai stok karbon, sejumlah studi pun telah mengukur stok karbon yang menggunakan metode lapangan atau dengan satelit penginderaan jauh (Jachowski et al., 2013; Friess et al., 2016). Studi ini menunjukkan bahwa mangrove di Singapura dapat menyimpan emisi karbondioksida tahunan dari 621.000 penduduk dan hutan bakau di Indonesia berkontribusi hingga $31 \%$ dari emisi karbon tahunan dari perubahan penggunaan lahan (Friess et al., 2016), meskipun Indonesia hanya menyumbang $6 \%$ dari seluruh deforestasi di negara ini (Mudiyarso et al., 2015).

Pertumbuhan penduduk yang semakin meningkat menimbulkan penekanan terhadap sumber daya alam. Seperti adanya pembangunan di wilayah pesisir sekitar kawasan hutan mangrove, yang mana wilayahnya belum dilakukan dengan bijaksana dan berwawasan lingkungan. (Muhaerin,2008).

Salah satu kemampuan mangrove dengan mengembangkan wilayahnya kearah laut merupakan salah satu peran penting dalam pembentukan lahan baru. Akar mangrove dapat menstabilkan dengan substrat lumpur, pohonnya dapat mengurangi hempasan gelombang sementara vegetasi mangrove tersebut dapat merangkap sedimen. Peranan mangrove dalam menunjang kegiatan perikanan pantai dapat disarikan dalam dua hal. Pertama, mangrove berperan penting dalam siklus hidup berbagai jenis ikan, udang dan moluska (Davies \& Claridge, 1993), karena lingkungan mangrove menyediakan perlindungan dan makanan berupa bahan-bahan organik yang masuk kedalam rantai makanan. Kedua, mangrove merupakan pemasok bahan organik, sehingga dapat menyediakan makanan untuk organisme yang hidup pada perairan sekitarnya (Mann, 1982).

Hutan mangrove yang paling luas di Indonesia ialah terdapat di Irian jaya yaitu sekitar 1.350.600 ha (38\%), kemudian Kalimantan yaitu sekitar 978.200 ha (28\%), terakhir Sumatera dengan luas sekitar 673.000 ha (19\%) (Dit. Bina Program INTAG, 1996).

Provinsi Riau memiliki kawasan mangrove seluas 206.292.642 hektar (2008). Luasan mangrove tersebut di lima kabupaten 
yaitu 55299.937 hektar di Kabupaten Bengkalis, 120895.898 hektar di Kabupaten Indragiri Hilir, 8976.645 hektar di Kabupaten Pelalawan, 19704.469 hektar berada di Kabupaten Rokan Hilir dan 1415.693 hektar berada di Kabupaten Siak (Bakosurtanal 2009).

Kabupaten Siak juga memiliki hutan mangrove yang saat ini sedang berupaya mengembangkan beberapa area untuk menjadi lokasi wisata, seperti yang sudah banyak dikenal masyarakat yaitu ekowisata mangrove Mengkapan. Baru-baru ini muncul lagi satu objek wisata alam yaitu, hutan mangrove Rawa Mekar Jaya. Kawasan ini berada di Kampung Rawa Mekar Jaya, Kecamatan Sungai Apit, Kabupaten Siak, dengan luasan sekitar 25 hektar. (Pengelola Wisata)

Ekowisata merupakan mata pencaharian alternatif bagi masyarakat pesisir yang dapat menambah pendapatan mereka. Selain itu dalam pengelolaan ekowisata dan strategi konservasi hutan mangrove, keterlibatan para stakeholders sangat berperan penting. Proyek ekowisata dapat berhasil jika stakeholders melaksanakan peran mereka dalam pengelolaan ekowisata maupun konservasi hutan mangrove (Satyanarayana dkk., 2012).

Ekowisata tidaklah hanya bertujuan untuk keuntungan usaha wisata saja. Namun adapun dampak pariwisata terhadap masyarakat dan sumber daya lingkungan, akan memperkuat masyarakat dalam mengembangkan dan mengelola pariwisata (Islam, dkk, 2011)

Kelestarian lingkungan untuk tetap dapat mengeksplor alam namun tetap memperhatikan lingkungan tersebut ialah dengan salah satu cara yaitu ekowisata. Ecotourism atau ekowisata atau pariwisata ekologi dikategorikan dari pariwisata berkelanjutan (sustainable tourism) atau salah satu segmen pasar dari pariwisata berbasis lingkungan alam (Fandeli, 2005).

Ekowisata mangrove merupakan objek wisata yang berwawasan lingkungan dimana wisata tersebut mengutamakan aspek keindahan yang alami dari hutan mangrove serta fauna yang hidup di sekitarnya tanpa harus merusak ekosistem tersebut. Untuk membuat wisatawan menjadi tertarik ialah disebabkan oleh hutan mangrove yang mempunyai ciri khas yang khusus dan memiliki banyak fauna dan flora yang hidup disekitarnya tersebut.

Ekowisata juga dapat memiliki dampak yang dapat diamati pada luasan areal mangrove. Analisis penginderaan jauh oleh (Shabuddin et al., 2012) menunjukkan bahwa beberapa penyebab hilangnya mangrove dapat dikaitkan dengan kegiatan ekowisata. Yang pertama, mangrove dibersihkan untuk pengembangan hotel dan perumahan 
untuk wisatawan, kedua mangrove hilang karena pembangunan dermaga dan meningkatnya lalu lintas kapal yang akan melemahkan dan mengikis tepi sungai bakau. Sementara batas kecepatan dan kontrol lalu lintas diperkenalkan untuk mengurangi erosi yang digerakkan oleh kapal namun langkah-langkah ini sulit untuk ditegakkan.

Ada sekitar 3 juta hektar hutan mangrove di Indonesia tumbuh di sepanjang 95.000 garis pesisir pantai. Jumlah tersebut mewakili $23 \%$ dari keseluruhan ekosistem mangrove di dunia (Giri et al., 2011). Mangrove di Kabupaten Siak tumbuh di pesisir depan pantai sehingga mangrove tersebut dapat berfungsi sebagai kawasan lindung dari hempasan gelombang dan badai. Pemanfaatan ekosistem mangrove untuk kegiatan ekowisata merupakan rangkaian dari kegiatan konservasi dan rehabilitasi yang dilakukan di dalam kawasan mangrove baik pada areal mangrove yang sudah rusak maupun pada areal yang baru untuk tujuan ekstensifikasi atau penambahan luasan areal mangrove.

Panjang areal yang terabrasi di Sungai Apit, 9.620 meter dengan tinggi surut serendah 55 meter.Pantai Buton sampai dengan Sei. Rawa dengan panjang pantai kurang lebih 1.380 meter dan lebar kurang lebih 45 meter dari tinggi surut terendah ( Kondur Petroleum S.A, 2002). Karena tingginya tingkat abrasi dan tekanan aktifitas warga sekitar seperti menebang pohon mangrove berdampak pada penurunan kualitas lingkungan ekosistem pesisir yang mengakibatkan sejumlah kawasan mangrove semakin berkurang bahkan rusak. sehingga perlu upaya pengembangan ekowisata mangrove melalui kegiatan ekowisata sebagai salah satu cara melestarikan ekosistem pesisir.

\section{METODE PENELITIAN}

\section{Waktu dan tempat penelitian}

Penelitian ini dilaksanakan pada bulan Desember-Januari yang berada di kawasan hutan mangrove di desa Rawa Mekar Jaya, Sungai Apit, Kabupaten Siak, Riau. Sekitar 3 jam dari pusat kota siak, atau 5 jam jika dari Pekanbaru.

\section{Bahan dan alat}

Alat-alat yang digunakan dalam penelitian ini adalah buku panduan mangrove untuk mengidentifikasi jenis mangrove, Global Positioning System (GPS), kompas, meteran, Kamera Hp, buku tulis dan alat tulis.

\section{Metode pengambilan sampel}

Pengambilan sampel di lokasi stasiun pengamatan Rawa Mekar Jaya ini ialah dengan metode stratified sampling. Pada setiap lokasi pengamatan sampel dibuat petak-petak contoh (plot) berbentuk persegi empat dengan ukuran:

a) $2 \mathrm{x} 2 \mathrm{~m}$ untuk semai (diameter batang $<2 \mathrm{~cm}$ dan tingginya $<1 \mathrm{~m}$ 
b) $5 \times 5 \mathrm{~m}$ untuk jenis pancang yaitu diameter batang 2-10 cm dengan tinggi $>1 \mathrm{~m}$.

c) $10 \times 10 \mathrm{~m}$ untuk jenis pohon yaitu diameter batang $>10$ $\mathrm{cm}$ dan tingginya $>1,3 \mathrm{~m}$

\section{Metode Analisis Data}

1. Analisis Kesesuaian

Kegiatan wisata yang akan dikembangkan harus disesuaikan dengan potensi sumberdaya dan peruntukannya. Setiap kegiatan wisata mempunyai persyaratan sumberdaya dan lingkungan yang sesuai objek wisata yang akan dikembangkan. Rumus yang digunakan untuk kesesuaian wisata mangrove adalah (Yulianda, 2007):

$$
I K W=\frac{N i}{N M a x} \times 100 \%
$$

Keterangan:

IKW : Indeks kesesuaian ekosistem untuk wisata mangrove

(Sesuai:83\%

100\%, Sesuai Bersyarat: 50\%

- <83\%, Tidak Sesuai: <50)

$\mathrm{Ni} \quad$ : Nilai parameter ke-i (Bobot x Skor).

Nmax : Nilai maksimum dari kategori wisata mangrove

\section{Analisis SWOT}

Analisis SWOT ialah melakukan identifikasi faktor-faktor strategi untuk melakukan identifikasi SWOT yaitu (Strength), (Weakness), (Opportunity), (Threats), faktor-faktor yang dimaksud ialah faktor internal dan faktor eksternal. (Rangkuti, 2005 dan Salusu, 1996)

Adapun langkah-langkah analisis SWOT sebagai berikut :

a. Meingidentifikasi kekuatan (S), Kelemahan (W), Peluang (O), dan ancaman (T) dari hasil pengamatan

b. Menentukan strategi SWOT yang dilakukan.

c. Setelah itu memilih 5 point penting dari setiap komponen. 
HASIL DAN PEMBAHASAN

\begin{tabular}{|c|c|}
\hline Parameter & Hasil \\
\hline Ketebalan Mangrove & Ketebalan mangrove $50 \mathrm{~m}$ \\
\hline Kerapatan Mangrove & $\begin{array}{l}\text { Ada dua tingkat kerapatan yaitu rendah dan } \\
\text { sedang. }\end{array}$ \\
\hline Jenis Mangrove & $\begin{array}{l}\text { Ada } 8 \text { jenis mangrove yaitu dari Rhyzophora } \\
\text { stylosa (Bakau Merah) avicennia Marina (Api- } \\
\text { api Putih), Bruguiera spp, Xylocarpus } \\
\text { Granatum (Nyirih), Lumnitzera spp , Nypa } \\
\text { Frutican (nipah), Soneratia caseolaris } \\
\text { (Berembang), Heriteiria Littoralis (Dungun). }\end{array}$ \\
\hline Pasang Surut (m) & $\begin{array}{l}\text { Tipe pasang surut di kawasan Mangrove Rawa } \\
\text { Mekar Jaya adalah Pasang surut harian tunggal } \\
\text { (Diurnal Tide) yaitu merupakan pasang surut } \\
\text { yang hanya terjadi satu kali pasang dan satu kali } \\
\text { surut dalam satu hari. } 12 \text { jam waktu pasang dan } \\
12 \text { jam waktu surut. Kisaran pasang terendah } 2 \\
\text { m yaitu pada bulan januari-Oktober, sedangkan } \\
\text { psang tertinggi sampai dengan } 5 \text { meter yaitu } \\
\text { pada bulan November-Desember }\end{array}$ \\
\hline Obyek Biota & $\begin{array}{l}\text { Keberadaan Fauna Ekosistem Mangrove di } \\
\text { Rawa Mekar Jaya Kelompok fauna daratan } \\
\text { (terestrial) adalah jenis burung seperti Burung } \\
\text { Serindit, Pelatuk Raja Udang, Murai Hitam dan } \\
\text { jenis reptil seperti biawak (Varanus salvator), } \\
\text { ular air (Natrix sp.), ular bakau, ular daun, ular } \\
\text { tiung dan kadal (Mabouia multifasciata). } \\
\text { Mamalia seperti monyet, lutung, berang- } \\
\text { berang. Kelompok fauna perairan (akuatik) di } \\
\text { daerah adalah jenis ikan seperti ikan sembilang, } \\
\text { Duri, Ketutu. jenis moluska seperti siput dan } \\
\text { blongan. jenis krustasea seperti udang } \\
\text { (Metapenaeus sp.) udang galah } \\
\text { (Macrobrachium rosenbergii), lokan. }\end{array}$ \\
\hline
\end{tabular}

\section{Kesesuaian Ekowisata Mangrove} Rawa Mekar Jaya

Beberapa parameter yang dijadikan untuk pertimbangan dalam penentuan indeks kesesuaian wisata ialah seperti ketebalan mangrove, kerapatan mangrove, jenis mangrove, pasang surut dan obyek biota. Parameter tersebutlah yang yang diteliti di lokasi penelitian dan terdapat 4 titik pengamatan yang dilakukan agar dapat dikategorikan sebagai kategori sesuai bersyarat dengan indeks kesesuaian wisata yaitu $50 \%-83 \%$.

Ekowisata pesisir dan laut merupakan bentuk wisata yang mengarah ke metatourism. Artinya, ekowisata pesisir dan laut tidak menjual tujuan atau objek melainkan menjual filosofi dan rasa. Berdasarkan aspek inilah ekowisata pesisir dan laut tidak akan mengenal kejenuhan pasar (Tuwo, 2011)

Penggalian potensi dan nilai kawasan ekosistem mangrove merupakan prioritas utama dalam pengelolaan ekowisata kawasan mangrove, dengan tujuan untuk dapat mengetahui seberapa besar potensi dan nilai tersebut dapat dimanfaatkan untuk meningkatkan pendapatan daerah yang berdasar prinsip prinsip keadilan dan kemandirian sehingga pada akhimya akan meningkatkan kesejahteraan masyarakat. Potensi keanekaragaman flora dan fauna merupakan modal dalam pengembangan ekowisata. Semakin banyak potensi daya tarik wisata alam yang ada pada suatu kawasan akan semakin menarik minat wisatawan untuk berkunjung pada 
kawasan tersebut (Purnomo et al. 2013). Kegiatan wisata yang akan dikembangkan hendaknya disesuaikan denganpotensi sumberdaya dan peruntukannya. Indeks kesesuaian ekologis dapat mengidentifikasikan apakah suatu ekosistem sesuai (S), sesuai bersyarat (SB), atau tidak sesuai (N) untuk suatu kegiatan wisata. Kesesuaian wisata mangrove mempertimbangkan 5 parameter dengan 4 klasifikasi penilaian. Parameter parameter tersebut adalah ketebalan mangrove, kerapatan mangrove, jenis mangrove, pasang surut dan obyek biota. Parameter ketebalan mangrove diperoleh dari Pengukuran di lapangan Kerapatan mangrove diperoleh dari hasil interpretasi citra dengan koreksi lapang pada beberapa titik pada saat pengamatan mangrove. Parameter jenis mangrove diperoleh dari hasil pengamatan mangrove dan pengamatan di lapangan. Parameter Pasang surut diperoleh dari prediksi pasang surut yang telah dikoreksi dan Parameter Obyek biota diperoleh dari pengamatan di lapangan.

Berdasarkan hasil penelitian yang dilakukan maka dapat diketahui indeks kesesuaian untuk kawasan wisata yang dapat dilihat dalam tabel dibawah ini:

Tabel 2: Indeks Kesuaian Kawasan untuk wisata mangrove Rawa Mekar

\begin{tabular}{|c|c|c|c|}
\hline Stasiun & $\begin{array}{c}\text { Total } \\
\text { skor }\end{array}$ & $\begin{array}{c}\text { Indeks } \\
\text { kesesuaian } \\
\text { wisata }\end{array}$ & $\begin{array}{c}\text { Tingkat } \\
\text { kesesuaian }\end{array}$ \\
\hline 1 & 25 & $64 \%$ & SB \\
\hline 2 & 24 & $61 \%$ & SB \\
\hline 3 & 21 & $53 \%$ & SB \\
\hline 4 & 23 & $58 \%$ & SB \\
\hline
\end{tabular}

Sumber: Pengolahan data Primer

Berdasarkan indeks kesesuaian ekosistem untuk wisata mangrove di lokasi penelitian tergolong ke dalam kategori
Sesuai Bersyarat (SB) untuk pengembangan ekowisata mangrove. Hal ini dibuktikan dari pengamatan secara ekologi serta pemberian skor atas masingmasing parameter di setiap stasiun. Pada Stasiun 1 total skor adalah 25 dari skor maksimum 39 dan nilai IKW nya $64 \%$ dengan kategori Sesuai Bersyarat. Selanjutnya pada stasiun 2 didapatkan total skor 24 dari skor maksimum 39 dan nilai IKW nya adalah $61 \%$ dengan kategori Sesuai Bersyarat. Pada stasiun 3 didapatkan total skor 21 dari skor maksimum 39 dan nilai IKW nya adalah 53\% dengan kategori Sesuai Bersyarat. Selanjutnya pada stasiun 4 didapatkan total skor 23 dari skor maksimum 39 dan nilai IKW nya adalah 58\% dengan kategori Sesuai Bersyarat. Kategori Sesuai Bersyarat (SB) menunjukan bahwa untuk menjadikan lokasi ini sebagai kawasan wisata, maka kawasan tersebut perlu dikelola terlebih dahulu misalnya dengan melakukan kegiatan penanaman mangrove selama 5-7 tahun. Berdasarkan parameter ekologis yang digunakan dalam menghitung indeks kesesuaian kawasan mangrove untuk ekowisata, yang paling berpotensi untuk dikembangkan sebagai kawasan wisata adalah stasiun 2 dan 3 . Hal ini didukung oleh keadaan parameter ekologis mangrove di stasiun 2 dan 3 jenis spesies mangrove dan fauna mangrove yang ditemukan lebih bervariasi.

\section{Strategi pengembangan}

Pengembangan ekowisata harus ada kerja sama antara masyarakat, pemerintah dan sektor swasta untuk mendukung dan memperkuat usaha ekowisata. Potensi ekowisata yang dimiliki merupakan kunci untuk pengembangan ekowisata/wisata, dengan memanfaatkan peluang dengan sebaik mungkin. 
Terciptanya suatu keberhasilan dalam pengembangan ekowisata ialah karena dipengaruhi oleh berberapa faktor yang diantaranya yaitu adanya keterlibatan masyrakat dalam menjalankan terwujudnya kegiatan ekowisata sehingga mampu menciptakan rasa nyaman dan aman terhadap wisatawan serta menjalin hubungan kerja berkelanjutan dengan stakeholder yang terlibat.

Berdasarkan analisis maka diperoleh faktor-faktor internal dan eksternal yang kemudian dapat menentukan strategi SWOT. Hasil penelitian menunjukkan bahwa strategi untuk pengembangan ekowisata mangrove di Desa Rawa Mekar Jaya ialah sebagai berikut:

Berdasarkan analisis yang mempertimbangkan kepentingan faktorfaktor eksternal dan internal serta keterkaitan antar faktor-faktornya (analisis SWOT) maka diperoleh alternatif strategi pengembangan ekowisata mangrove di Desa Rawa Mekar Jaya. Analisis SWOT didapatkan karena ekowisata mangrove ini telah dibandingkan dengan ekowisata mangrove yang lainnya yang ada di Kecamatan Sungai Apit, Kabupaten Siak. Berdasarkan Hasil Penelitian, strategi pengembangan untuk Ekowisata Mangrove Rawa Mekar Jaya ini ialah sebagai berikut:

1. Meningkatkan usaha pengelolaan ekosistem mangrove melalui kegiatan ekowisata

2. Menambah area parkir. Karena area parkir masih kurang mencukupi.

3. Menambah toilet/wc.

4. Menjaga obyek wisata mangrove dengan tetap memperhatikan daya dukung kawasan.
5. Memberikan promosi baik lewat internet maupun media lainnya untuk menarik minat wisatawan berwisata mangrove

6. Meningkatkan dan mempromosikan usaha hasil pengolahan produk dari mangrove kepada wisatawan.

7. Memperbaiki jalan yang masih rusak yang menuju kawasan ekowisata mangrove Rawa Mekar Jaya.

8. Memberikan pendidikan lingkungan/konservasi kepada setiap wisatawan dengan cara menjaga kebersihan di tempat wisata, dll.

9. Diadakannya pelatihan tambahan kepada kelompok masyarakat pengelola kawasan supaya masyarakat pengelola kawasan wisata bisa berbagi tentang pendidikan lingkungan kepada wisatawan.

Dari hasil analisis SWOT ditemukan 9 poin rencana kegiatan pengelolaan pengembangan ekowisata, untuk diperhatikan agar ekowisata dapat meningkatkannya di ekowisata mangrove Desa Rawa Mekar Jaya ini.

Maka diperoleh empat strategi prioritas utama untuk rencana pengembangan ekowisata mangrove di Ekowisata Mangrove Rawa Mekar Jaya. Strategi-strategi tersebut adalah meningkatkan upaya penanaman mangrove pada wilayah pengembangan ekowisata mangrove sehingga mangrove dapat memenuhi kriteria sangat sesuai untuk kawasan wisata yang baik berdasarkan Indeks Kesesuaian Wisata (IKW), (1) meningkatkan partisipasi masyarakat lokal dalam mengembangkan kemampuan dan kreatifitas usaha wisata, 
seperti pembuatan souvenir dan (2) mempromosikan wisata mangrove seperti mempromosikan wisata mangrove lewat internet maupun media lainnya untuk menarik wisatawan, (3) Menjaga obyek wisata mangrove dengan tetap memperhatikan daya dukung kawasan serta (4) meningkatkan peran serta dinas terkait melalui penambahan sarana dan prasarana pendukung kegiatan wisata.

Strategi ini dibuat dengan pertimbangan bahwa banyak masyarakat yang tidak tahu akan manfaat dan fungsi penting dari ekosistem mangrove sehingga mereka tidak peduli akan kelestarian ekosistem mangrove bahkan cenderung merusak lingkungan tersebut dengan mendapatkan manfaat langsung dari hutan mangrove, seperti menebang pohon mangrove secara besar baik untuk kayu bakar maupun dengan tujuan pembukaan lahan untuk pemukiman dan lain sebagainya tanpa melakukan rehabilitasi untuk menjaga kelestarian lingkungan ekosistem mangrove tersebut.

Pemerolehan strategi pengembangan merupakan tindak lanjut setelah dilakukan hasil analisis SWOT. Berdasarkan hasil analisis SWOT, diperoleh faktor kekuatan dijadikan sebagai acuan dalam strategi pengembangan ekowisata, sedangkan kelemahan dijadikan sebagai permasalahan yang harus diperbaiki segera agar terciptanya strategi pengembnagan ekowisata yang optimal, dan sesuai dengan harapan pada saat ini dimana pariwisata telah menjadi sektor sebagai pembangunan ekonomi yang dapat dilihat berdasarkan jumlah pengunjung yang mengunjungi kawasan wisata.

Wisatawan ekowisata mangrove Rawa Mekar Jaya ini telah banyak wisatawan yang berkunjung, mulai dari wisatawan lokal maupun wisatawan mancanegara. Wisatawan yang berkunjung tersebut akan dapat menggerakkan perekonomian suatu daerah.

\section{KESIMPULAN}

1. Indeks Kesesuaian kawasan untuk Wisata mangrove di ekowisata mangrove Rawa Mekar Jaya tergolong ke dalam kategori Sesuai

Bersyarat (SB). Pada stasiun 1 kesesuaiannya adalah $64 \%$, stasiun 2 kesesuaiannya ialah $61 \%$, stasiun 3 kesesuaiannya ialah $53 \%$, stasiun 4 kesesuaiannya ialah $58 \%$.

2. Strategi pengembangan ekowisata mangrove di desa Rawa Mekar Jaya adalah meningkatkan upaya penanaman mangrove pada wilayah pengembangan ekowisata mangrove sehingga mangrove memenuhi kriteria sesuai.. Meningkatkan partisipasi masyarakat lokal dalam mengembangkan kemampuan dan kreatifitas usaha wisata, seperti pembuatan souvenir dan mempromosikan wisata mangrove melalui internet maupun lewat media pendukung lainnya agar menarik wisatawan, memperhatikan daya dukung kawasan wisata serta meningkatkan penambahan sarana dan prasarana pendukung kegiatan wisata.

\section{DAFTAR PUSTAKA}

Bakosurtanal. 2009. Luas Kawasan Mangrove Per Kabupaten. jurnal Pengembangan Ekowisata dikawasan Mangrove Desa Anak Setatah Kabupaten

Kepulauan Meranti Provinsi Riau. Institut Pertanian Bogor, Bogor.

Davies, J. \& G. Claridge. 1993. Wetland Benefits. The Potential forWetlands to Support and Maintain 
Development. Asian Wetland Bureau, International Waterfowl \& Wetlands Research Bureau, Wetlands for the America's.

Donato, D. C., Kauffman, J. B Murdiyarso, D., Kurnianto, S., Stidham, M., \& Kanninen, M. 2011. Mangroves Among The Most Carbon-Rich Forests In The Tropics. Nature Geoscience, volume 4 (5), 293-297.

Fandeli, C dan Nurdin, M, 2005. Pengembangan Ekowisata Berbasis Konservasi di Taman Nasional. Fakultas Kehutanan Universitas Gajah Mada, Yogyakarta.

Friess DA. Richards DR, Phang VXH. 2016b. Mangrove Forest Store High Densities of Carbon Across the Tropical Urban Lanscape of Singapore. Urban Ecosystem volume (19), 795- 810.

Giri C, Ochieng E, Tieszen LL, Zhu Z, Shing A, Loveland T, Masek J, Duke N. 2011. Status and Distribution of Mangrove Forest of the World Using Earth Observation Satellite Data. Global Ecology and Biogeography volume 20, 154-159.

Islam, S, Howlader, A, and Monirul, I. 2011. Community Based Ecotourism in The Sundarbans of Bangladesh. Rajagiri Journal of Social Development. Vol 3, 31-50 Jachowski NRA, Quak MSY, Friess DA, Duangnamon D, Webb EL, Ziegler AD. 2013. Mangrove Biomass Estimation in Southwest Thailand Using Machine Learning. Applied Geography Vol 45, 311-321.

Kondur Petroleum S.A. (2002). Laporan Pelaksanaan Program Penanaman
Hutan Tanaman Pantai Tahun 2002. Kepulauan Meranti: Kondur Petroleum S.A.

Mann, K.H. 1982. Ecology of Coastal Waters. A Systems Approach. Studies in Ecology, Blackwell Scientific Publications, 322 hal.

Mudiyarso D, Purbopuspito J, Kauffman JB, Warren MW, Sasmito SD, Donato DC, Manuri S, Krisnawati H, Taberima S, Kurnianto S. 2015. The Potential of IndonesiMangrove Forest for Global Climate Change Mitigation. Nature Climate Change volume 5, 1089-1092.

Muhaerin M. 2008. Kajian Sumberdaya Ekosistem Mangrove untuk Pengelolaan Ekowisata di Estuaria Perancak, Jembrana, Bali. Departemen Manajemen Sumberdaya Perairan. Fakultas Perikanan dan Ilmu Kelautan. Institut Pertanian Bogor, Bogor.

Purnomo H, Sulistyantara B, Gunawan A. 2013. Peluang Usaha Ekowisata di Kawasan Cagar Alam Pulau Sempu, Jawa Timur. Jurnal Penelitian Sosial dan Ekonomi Kehutanan, 10 (4): 247-263.

Rangkuti, F. 2004. Analisis SWOT. Teknik Membedah Kasus Bisnis. Gramedia Pustaka Utama: Jakarta.

Shahbudin S, Zuhairi A, Kamaruzzaman BY, 2012. Impact of Coastal Development on Mangrove Cover in Killim River, Langkawi Island, Malaysia. Journal of Forestry Research volume 23, 185-190

Salusu, J. (1996). Pengambilan Keputusan Stratejik Untuk Organisasi Publik Dan Organisasi Non Profit. PT. Gramedia Pustaka Utama: Jakarta.

Satyanarayana. B and Friends. 2012. A Socio-Ecological Assessment Aiming at Improved Forest Resource Management and Sustainable Ecotouris Development 
in the Mangroves of Tanbi

Wetland National Park, the

Gambia, West Africa. AMBIO,

volume 41, 513-526.

Tuwo A. 2011. Pengelolaan Ekowisata

Pesisir dan Laut: Pendekatan

Ekologi, Social Ekonomi dan

Sarana Wilayah. Brilian

Internasional. Surabaya.

Yulianda, F. 2007. Ekowisata Bahari Sebagai Alternatif Pemanfaatan Sumberdaya Pesisir Berbasis

Konservasi. Standar Sains: Bogor. 